\title{
Altered language network activity in young people at familial high-risk for schizophrenia
}

\section{Citation}

Thermenos, H.W., S. Whitfield-Gabrieli, L.J. Seidman, G. Kuperberg, R.J. Juelich, S. Divatia, C. Riley, et al. 2013. "Altered Language Network Activity in Young People at Familial HighRisk for Schizophrenia." Schizophrenia Research 151 (1-3) (December): 229-237. doi:10.1016/ j.schres.2013.09.023.

\section{Published Version}

doi:10.1016/j.schres.2013.09.023

\section{Permanent link}

http://nrs.harvard.edu/urn-3:HUL.InstRepos:28539564

\section{Terms of Use}

This article was downloaded from Harvard University's DASH repository, and is made available under the terms and conditions applicable to Other Posted Material, as set forth at http:// nrs.harvard.edu/urn-3:HUL.InstRepos:dash.current.terms-of-use\#LAA

\section{Share Your Story}

The Harvard community has made this article openly available.

Please share how this access benefits you. Submit a story.

\section{Accessibility}


(C) 2013 Elsevier B.V. All rights reserved.

*Corresponding author at: Athinoula A. Martinos Center for Biomedical Imaging, Building 149, 2nd Floor (Room 2602E), 13th Street, Charlestown, MA 02129, USA. Tel.: +1 617726 6043; fax: +1 617726 4078. hthermen@ bidmc.harvard.edu (H.W. Thermenos).

\section{Contributors}

H.W. Thermenos developed the study design, collected and analyzed the data, and composed the manuscript. S. Whitfield-Gabrieli developed the study design, supervised statistical analyses and assisted in manuscript composition. L.J. Seidman consulted on study design, supervised data collection and assisted in manuscript composition. G. Kuperberg developed the study design and assisted in manuscript composition. R. J. Juelich coordinated the study, collected the data and assisted in manuscript composition. S. Divatia assisted in statistical analysis of the data and manuscript composition. C. Riley assisted in statistical analysis of the data and manuscript composition. G.A. Jabbar coordinated the study, collected the data and assisted in manuscript composition. M. E. Shenton consulted on study design and assisted in manuscript composition. M Kubicki consulted on study design and assisted in manuscript composition. T. Manschreck consulted on study design and assisted in manuscript composition. M. S. Keshavan consulted on study design, supervised data collection and assisted in manuscript composition. L.E DeLisi wrote the grant that funded the study, developed the study design, supervised data collection, and assisted in manuscript composition.

\section{Conflict of interest}

Dr. Thermenos reports no financial disclosures or conflicts of interest.

Dr. Whitfield-Gabrieli reports no financial disclosures or conflicts of interest.

Dr. Seidman reports no financial disclosures or conflicts of interest.

Dr. Kuperberg reports no financial disclosures or conflicts of interest.

Mr. Juelich reports no financial disclosures or conflicts of interest.

Ms. Divatia reports no financial disclosures or conflicts of interest.

Mr. Riley reports no financial disclosures or conflicts of interest.

Ms. Jabbar reports no financial disclosures or conflicts of interest.

Dr. Shenton reports no financial disclosures or conflicts of interest.

Dr. Kubicki reports no financial disclosures or conflicts of interest.

Dr. Manschreck reports no financial disclosures or conflicts of interest.

Dr. Keshavan reports no financial disclosures or conflicts of interest.

Dr. DeLisi reports no financial disclosures or conflicts of interest. 


\section{Abstract}

Background-Abnormalities in language and language neural circuitry are observed in schizophrenia (SZ). Similar, but less pronounced language deficits are also seen in young firstdegree relatives of people with SZ, who are at higher familial risk (FHR) for the disorder than the general population. The neural underpinnings of these deficits in people with FHR are unclear.

Methods-Participants were 43 people with FHR and 32 comparable controls. fMRI scans were collected while participants viewed associated and unrelated word pairs, and performed a lexical decision task. fMRI analyses conducted in SPM8 examined group differences in the modulation of hemodynamic activity by semantic association.

Results-There were no group differences in demographics, IQ or behavioral semantic priming, but FHR participants had more schizotypal traits than controls. Controls exhibited the expected suppression of hemodynamic activity to associated versus unrelated word pairs. Compared to controls, FHR participants showed an opposite pattern of hemodynamic modulation to associated versus unrelated word pairs, in the left inferior frontal gyrus (IFG), right superior and middle temporal gyrus (STG) and the left cerebellum. Group differences in activation were significant, FWE-corrected for multiple comparisons $(\mathrm{p}<0.05)$. Activity within the IFG during the unrelated condition predicted schizotypal symptoms in FHR participants.

Conclusions-FHR for SZ is associated with abnormally increased neural activity to semantic associates within an inferior frontal/temporal network. This might increase the risk of developing unusual ideas, perceptions and disorganized language that characterize schizotypal traits, potentially predicting which individuals are at greater risk to develop a psychotic disorder.

\section{Keywords}

Schizophrenia; Functional MRI; High-risk; Language; Genetics; Semantic priming

\section{Introduction}

Schizophrenia (SZ) has been characterized as a disorder of language, thought and communication since its earliest inception (Bleuler, 1950; Andreasen, 1979). Deficits range from the single word to whole discourse level (Goldberg et al., 1998; Titone et al., 2000; Kuperberg and Goldberg, 2006; Kuperberg, 2010a,b) and have been detected prior to or during the first episode (Hoff et al., 1999; Fuller et al., 2002; Hoff et al., 2005). It has been suggested that language deficits in $\mathrm{SZ}$ arise from an abnormal spread of activity across semantic networks, due to abnormalities in both automatic and controlled mechanisms of semantic retrieval (Manschreck et al., 1988; Spitzer et al., 1994; Kuperberg and Goldberg, 2006; Kreher et al., 2008).

One way of examining the spread of activity across semantic networks is through semantic priming (Meyer and Schvaneveldt, 1971; Neely, 1991). Semantic priming describes the faster response to a target word when it is preceded by a semantically associated word compared to an indirectly associated or unrelated word. There is some inconsistency in results of semantic priming experiments in patients with SZ. While some behavioral (Manschreck et al., 1988; Spitzer et al., 1994; Moritz et al., 2001b) and electrophysiological 
studies (Kreher et al., 2008) have shown an exaggerated semantic priming effect in patients with SZ (Maher et al., 2005; Kuperberg et al., 2007), other studies reveal normal or reduced priming (Kuperberg et al., 2008a; Kreher et al., 2009).

Two factors that affect the direction of findings in priming studies of SZ are the presence of thought disorder in study participants, and the experimental design. Increased semantic priming effects (including priming responses to indirectly-related as well as directly-related primes) are generally reported when the patients with SZ have formal thought disorder (Manschreck et al., 1988; Spitzer et al., 1994; Moritz et al., 2001a, 2001b; Kreher et al., 2008), and/or when the experiment is designed to probe automatic semantic retrieval mechanisms (Neely, 1991; Spitzer et al., 1993, 1994; Moritz et al., 2001a, 2001b; Lecardeur et al., 2006; Pomarol-Clotet et al., 2008; Kreher et al., 2009). In the latter case, the effect of strategy, expectancy and general executive function on performance is circumvented using a number of techniques, including use of a short interval between the prime and target word (Stimulus Onset Asynchrony, or SOA). Alternatively, when participants are not selected based on the presence of thought disorder, or when the experiment is designed to probe controlled, strategic aspects of semantic prediction or retrieval, patients with SZ show normal or reduced priming effects relative to controls (Vinogradov et al., 1992; Barch et al., 1996; Ober et al., 1997; Besche-Richard et al., 2005; Kreher et al., 2009).

The neural basis of lexico-semantic processing is fairly well understood. Broadly, middle and inferior temporal cortices have been implicated in lexico-semantic storage and access (Van Petten and Luka, 2006; Lau et al., 2008; Lau et al., in press) while the left inferior frontal cortex (Broca's area) is thought to mediate controlled semantic retrieval and/or selection (Thompson-Schill et al., 1997, 1999; Wagner et al., 2001; Gold et al., 2006). fMRI studies of semantic priming in healthy individuals have demonstrated reduced activity to semantically associated versus unrelated word pairs within both temporal and inferior frontal regions ('association-induced suppression') (Kotz et al., 2002; Copland et al., 2003; Rissman et al., 2003; Matsumoto et al., 2005; Wheatley et al., 2005; Kuperberg et al., 2008b). Because fMRI is sensitive to the relatively slow hemodynamic response (integrating activity over seconds), it is not possible to distinguish neural responses to the prime vs. the target using this method alone. However, a recent study combining fMRI with event-related potentials (ERPs) and magnetoencephalography (MEG) suggests that automatic priming can lead to neural suppression within the left anterior temporal cortex between 300 and $500 \mathrm{~ms}$ (the N400 time window) following target onset (Lau et al., in press).

Consistent with altered semantic processing in SZ, fMRI studies of semantic priming in SZ have reported less association-induced suppression in left frontal and temporal regions (Han et al., 2007; Kuperberg et al., 2007), and sometimes even the opposite pattern of modulation, with more activity to semantically associated relative to unrelated pairs ('associationinduced enhancement') (Kuperberg et al., 2007). These abnormalities were seen even when behavioral semantic priming was normal. In inferior temporal cortices, the degree of association-induced enhancement in SZ predicted severity of positive thought disorder (Kuperberg et al., 2007). 
There is considerable debate about what drives hemodynamic response suppression versus enhancement in priming paradigms (Segaert et al., 2013). Kuperberg et al. (2007) speculated that the abnormal hemodynamic response enhancement in patients arose from a failure to inhibit activity within the temporal cortex to the related words, perhaps as a result of an inefficiency of left frontal cortex-mediated controlled processing. fMRI concatenates neural activity over a number of time scales, and thus, it may be that both inefficiency in frontal function and prolonged residual activation in the temporal cortex were captured by the overall increase in BOLD activity to the related (versus unrelated) words in patients. Results were interpreted to be consistent with associative hyperactivity and possible frontotemporal dysconnection in SZ (Kuperberg et al., 2007).

Altered frontotemporal responses during semantic priming in SZ are consistent with other neuroimaging data implicating frontotemporal alterations in SZ (Petty et al., 1995; Li et al., 2007a; Oertel et al., 2010). These include altered frontotemporal connectivity (Skudlarski et al., 2010; Voineskos et al., 2010; Wang et al., 2011), abnormalities in the structure of Broca's and other frontal regions (Sanfilipo et al., 2000; Shenton et al., 2001; Wible et al., 2001; Bartzokis et al., 2003; Kuperberg et al., 2003; Wisco et al., 2007), abnormalities within white matter tracts to and from the temporal lobe (Honer et al., 1995; Shenton et al., 2001; Kubicki et al., 2002; Burns et al., 2003; Hubl et al., 2004; Jones et al., 2006; Cui et al., 2010; Whitford et al., 2010; Cui et al., 2011; Kubicki et al., 2011) and altered fMRI activation during performance on a wide variety of language tasks (Sommer et al., 2001; Kubicki et al., 2003; Sommer et al., 2003; Weiss et al., 2003; Ragland et al., 2004; Sommer et al., 2004; Li et al., 2007a; Kuperberg et al., 2008c; Li et al., 2009; Oertel et al., 2010). It has been suggested that these abnormalities may result from early, possibly geneticallymediated alterations in the development of language circuits (Wyatt, 1996; Crow, 1997; Woolf, 1997; Crow, 2008) that occur prior to disease onset (Pantelis et al., 2003). Indeed, retrospective analysis of clinical data indicates early language and reading delays in people who later developed SZ (DeLisi et al., 1991; Hoff et al., 1999, 2005).

Language and frontotemporal alterations may also be a marker of disease risk. There is increasing evidence of language (Hallett et al., 1986; Ott et al., 2001; Cannon et al., 2002; Whalley et al., 2004; Bhojraj et al., 2009) and frontotemporal alterations in first-degree biological relatives of persons with SZ, who are at elevated or familial high-risk (FHR) to develop a psychotic disorder. Neuroimaging studies of participants with FHR reveal structural alterations, and in some cases, altered lateralization (Sommer et al., 2004; Li et al., 2009) in frontal and temporal regions. Structural abnormalities have been described in the posterior sylvian fissure (Honer et al., 1995), inferior frontal (McIntosh et al., 2004; Bhojraj et al., 2009, 2011; Li et al., 2012) and several temporal regions (McIntosh et al., 2004; Oertel et al., 2010; Goghari et al., 2011; Li et al., 2012) [e.g., Heschl's gyrus (Bhojraj et al., 2009, 2011), superior temporal gyrus (STG) (Rajarethinam et al., 2004) and the planum temporale (Oertel et al., 2010)]. Some fMRI studies of language in FHR participants (using diverse language tasks) have reported increased right inferior frontal activity (Sommer et al., 2004; Li et al., 2007b) (or decreased left-sided activity) (Li et al., 2007a), as well as abnormalities in temporal, parietal and cerebellar regions (Sommer et al., 2004; Whalley et al., 2004; Whyte et al., 2006; Rajarethinam et al., 2011). In one study, a functional connectivity analysis revealed reduced connectivity from inferior frontal to visual language 
processing regions ( $\mathrm{Li}$ et al., 2010). Taken together, these results suggest that abnormalities of frontotemporal pathways might increase vulnerability to develop SZ in FHR participants. What remains unclear, however, is whether participants with FHR show the more specific abnormalities in semantic associative activity that are thought to be central to SZ itself.

To address this question, we carried out a semantic priming fMRI study in young adult participants with FHR and low-risk controls, using the same set of stimuli and task that has previously been used to examine semantic activity in SZ (Kuperberg et al., 2007). We examined how the semantic association between prime and target word-pairs modulated lexical decision reaction times and hemodynamic activity in language-related brain regions. Analyses were carried out across the whole brain and in language-specific regions of interest, derived from previous studies of language in participants with FHR and studies of semantic priming in healthy controls and patients with SZ (inferior frontal gyrus and superior, middle and inferior temporal gyrus). We also examined the relationship between language-related brain activity, behavioral semantic priming and schizotypal symptoms. Based on previous work in SZ, we predicted that participants with FHR would exhibit association-induced enhancement (with more activity to the associated relative to unrelated word pairs) in inferior frontal and temporal regions (where controls exhibit associationinduced suppression). We predicted that differences in semantic association-induced brain activity in FHR participants would be associated with increased schizotypal symptoms.

\section{Methods and Materials}

\subsection{Participants}

Participants were 43 non-psychotic people with FHR (having at least one first-degree relative with a DSM-IV diagnosis of schizophrenia or schizoaffective disorder, and one 1st, 2nd or 3rd degree relative with a history of psychosis, suicide, psychiatric hospitalization or Axis I disorder), and 32 controls (with no family history of a psychosis in 1st, 2nd or 3rd degree relatives), who were group-matched in age (mean age 25, range 19-32), gender, ethnicity and handedness (all right-handed). FHR participants were recruited from Massachusetts and neighboring New England regions through brochures and advertisements and through the National Alliance on Mental Illness (NAMI). Controls were recruited from the same communities as the FHR participants via advertisement. Exclusion criteria for all participants were: lifetime history of DSM-IV psychotic disorder, English not the participant's native language, non-right-handedness (Annett, 1970), neurological illness, and IQ below 80 . Control participants were excluded if they had a family history of psychotic disorder, other major psychiatric illness or suicide. The Diagnostic Interview for Genetic Studies (DIGS) (Nurnberger et al., 1994; First et al., 1996) indicated the following diagnoses in the participants with FHR: 16 with major depression, 8 with anxiety disorder, 8 with attention deficit hyperactivity disorder, 6 with substance abuse, 4 with an eating disorder, and 2 with schizotypal personality disorder. The study was approved by the Human Participants Investigation Committee at Harvard Medical School, Beth Israel Deaconess Medical Center, Massachusetts Institute of Technology, Brigham andWomen's Hospital and Veterans Administration Boston Healthcare System, Brockton, Massachusetts. All participants provided written informed consent and were paid for their participation. 


\subsection{Psychiatric and neuropsychological assessments}

A medical and substance use history and family pedigree were obtained via interview. The Diagnostic Interview for Genetic Studies (DIGS) (Nurnberger et al., 1994; First et al., 1996) was administered by an experienced, trained interviewer, to establish the lifetime presence of any Axis I or II psychiatric disorder. Diagnoses based on the DIGS were made by the study Principal Investigator (L.E.D.). Schizotypal traits (magical thinking, ideas of reference, illusions, suspiciousness, psychotic-like symptoms, restricted emotion, social isolation/introversion, schizotypal social anxiety, and anger to slights) were assessed using the Structured Interview for Schizotypy (SIS) (Kendler et al., 1989). This interview provides an indication of attenuated psychotic symptoms which may be observed on a continuum, and to varying degrees in non-psychotic people at FHR for SZ. Subjects are given a score on each schizotypal trait ranging from 0 to 6 , with scores over 2 indicative of psychopathology. For each subject, scores were quantified as: 1) the number of schizotypal trait scores with a non-zero value, and 2) the number of schizotypal traits with a global score over 2. Mood on the day of scanning was assessed with the Profile of Mood States (POMS) (McNair et al., 1992). General intellectual ability (IQ) was prorated from Vocabulary and Block Design subtests of the Wechsler Adult Scale of Intelligence (WASI) (Wechsler, 1999). Relative hand preference was assessed using the Annett 23 item scale (Annett, 1970).

\subsection{Semantic priming paradigm}

During scanning, participants carried out a semantic priming paradigm with a lexical decision task, using stimuli developed for Kuperberg et al. (2007) and Kreher et al. (2006). These consisted of target words (e.g., stripes) that were paired with associated primes (tiger) or unrelated primes (truck) (methods used to establish the associative strength between prime-target word pairs in studies of controls are further detailed in Kreher et al. (2006) and Kuperberg et al. (2007)). In a third condition, targets were paired with indirectly related primes. In this study, however, we focus on the contrast between associated and unrelated word pairs as this provides the most robust measure of association-induced hemodynamic activity. All nonword targets were phonologically permissible strings in English and they were all derived from words that were unrelated to their primes (e.g., lion-soble). Stimuli were counterbalanced across the three lists.

During each of three 6 minute and 10 second fMRI runs, participants viewed a list of 200 stimulus pair trials: 50 associated, 50 unrelated and 50 indirectly related prime-target wordpairs, and 50 word-nonword trials. Each trial began with the prime $(500 \mathrm{~ms})$, a blank screen (300 $\mathrm{ms})$, a target $(500 \mathrm{~ms})$, and then another blank screen (300 ms) [thus, we used a fixed 800 millisecond stimulus onset asynchrony (SOA) between the onset of the prime and the onset of the target]. Between each word pair, a question mark appeared $(1100 \mathrm{~ms})$ followed by a blank screen $(300 \mathrm{~ms})$. The trial types appeared in pseudorandom order, interspersed among 100 visual fixation trials (where participants fixated on a plus sign for variable durations of 1000-8000 ms; mean, $3000 \mathrm{~ms}$ ). The random interleaving of these fixation or null-events among the word-pairs enabled the efficient estimation and deconvolution of the entire hemodynamic response (Burock et al., 1998). 
During the lexical decision task, participants decided as quickly and as accurately as possible whether the target was a real English word or a nonword, indicating their decisions by button press. Participants were trained on the task prior to scanning. Their accuracy and reaction times (RTs) were recorded.

\subsection{Neuroimaging}

Imaging was conducted on a Siemens TRIO TIM 3.0 Tesla full body MR scanner at the A.A. Martinos Imaging Center in the McGovern Institute for Brain Research at the Massachusetts Institute of Technology (MIT), using a 32 channel head coil. A localizer sequence was performed for placement of slices, followed by a coronal T2-weighted sequence to rule out unexpected neuropathology. During each of the three semantic priming task runs, whole-brain T2 $*$ weighted gradient echo EPI was acquired (TR/TE/Flip $=2000$ $\mathrm{ms} / 30 \mathrm{~ms} / 90^{\circ}, 32$ contiguous $4 \mathrm{~mm}$ thick slices, positioned parallel to anterior commissureposterior commissure line, echo spacing $=0.5$, bandwidth $=2300$, FOV $=200 \times 200$, matrix size $=64 \times 64)$. To accelerate fMRI acquisitions and minimize distortions, GRAPPA (Generalized Autocalibrating Partially Parallel Acquisition) with an acceleration factor of 2 was used. The fMRI sequences included prospective acquisition correction (PACE) for head motion (Thesen et al., 2000).

\subsection{Statistical analysis}

All (non-fMRI) variables were compared using ANOVAS and independent sample t-tests performed in the Statistical Package for the Social Sciences (SPSS) software. Accuracy (with which nonwords and words were correctly classified) was calculated as the percentage of items answered correctly. RTs were entered into a $2 \times 2$ ANOVA (with Group as the between-subjects factor and Association as the within-subjects factor).

Pre-processing of fMRI data [motion correction, co-registration, spatial normalization (using nonlinear volume-based techniques) and smoothing (with an $8 \mathrm{~mm}$ Gaussian filter)] and statistical analysis of semantic priming related modulation of blood-oxygen level dependent (BOLD) signal (activation and suppression) was examined using SPM8 (Department of Imaging Neuroscience, London, UK) (www.fil.ion.ucl.ac.uk/spm/) and in-house software (http://web.mit.edu/swg/software.html) running in the MATLAB environment (Mathworks, Inc.). Data were inspected for artifacts and motion using custom software ART (http:// web.mit.edu/swg/software.html).

\subsubsection{Semantic association-induced modulation of brain activity-First-level} analysis was implemented in SPM8. Estimated motion parameters, artifact-indicator covariates, and low-frequency components were explicitly modeled and their effects removed from the estimation of effects of interest. Contrasts of interest (Unrelated > Associated; Associated > Unrelated) were defined for each subject and entered into secondlevel group analyses. Group differences in activation were assessed using a 2 (Group) $\times 2$ (Association) ANOVA. Group differences in activation can be driven by differences in the Associated condition, the Unrelated condition, or both. Thus, to further characterize between-group differences, parameter estimates were extracted from the functional clusters that significantly differentiated the groups for the Associated and Unrelated conditions 
separately (with level of activity in each separate condition calculated relative to the baseline fixation). Parameter estimates for each condition relative to fixation baseline were then depicted in the graphs. In addition, we tested for effects of Association within the control and FHR participant groups separately across the whole brain using one-sample $t$ tests on the contrast images. Results were corrected for multiple comparisons across the whole brain or across a priori regions of interest, using the family-wise error correction, cluster-level significance of $p<0.05$. Bilateral language task-specific regions of interest were created using the Wakeforest University Pickatlas Tool (http://www.fmri.wfubmc.edu) and cortical parcellation methods developed at the Center for Morphometric Analysis (http:// www.cma.mgh.harvard.edu/), and defined as follows: inferior frontal gyrus (BA 44, 45, 47), orbitofrontal gyrus (BA 10, 11), lateral temporal cortex (including STG and MTG; BA 22, $42,21)$ and temporal fusiform cortex (BA 37, 20).

To test a priori hypotheses about relationships between brain activity, task performance and schizotypal symptoms, we carried out bivariate Pearson's correlations (or Spearman's, where appropriate) between the fMRI parameter estimates, behavioral semantic priming and schizotypal traits. For these analyses, parameter estimates for each condition (Unrelated > Fixation; Associated > Fixation) were extracted from predicted functional regions that distinguished the two groups (inferior frontal and temporal regions). Parameter estimates were correlated with 1) a behavioral semantic priming (quantified as the Unrelated condition mean RT-Associated condition mean RT) and 2) schizotypal traits [quantified as number of global SIS scores with a value in the abnormal range ( $>2)]$. Correlations were examined within the control and FHR participant groups separately. Correlations with a p-value $<0.05$ were reported as significant.

\section{Results}

\subsection{Demographic, neuropsychological and clinical characteristics}

There were no group differences in demographic variables, education or IQ(Table 1). Participants with FHR exhibited significantly greater scores on the tension/anxiety, anger/ hostility and fatigue subscales of the POMS, and a significantly higher number of positive SIS scores and number of global SIS scores $>2$.

\subsection{Behavioral semantic priming}

There was a significant main effect of Association on RTs $(F(1,73)=12.17, p=0.001)$, reflecting shorter RTs to directly associated than unrelated targets, i.e., a semantic priming effect. There was no difference in semantic priming between FHR and control participants, as reflected by the absence of a Group by Association interaction $(F(1,73)=0.31, p=0.58)$, and there were no overall differences in RTs between FHR and control participants $(\mathrm{F}(1,73)$ $=0.10, \mathrm{p}=0.76$ ). There were no effects of Association or Group, and no Association by Group interaction effect on accuracy (all Fs $<2.7$, ps $>0.10$ ).

\subsection{The modulation of hemodynamic activity by semantic association}

A $2 \times 2$ ANOVA revealed a significant interaction between Group and Association within the left inferior frontal gyrus (IFG), right superior and middle temporal gyrus (STG) and left 
cerebellum (Table 2, Fig. 1). Follow-up analyses to determine the source of this interaction were carried out in each of these regions by extracting the parameter estimates and examining each group separately (Fig. 1). In the left inferior frontal and left cerebellar regions, controls showed less activity to the associated than the unrelated word pairs, i.e. association-induced suppression. Participants with FHR, however, showed the opposite pattern in both these regions: more activity to the associated than the unrelated pairs, or association-induced enhancement. In the right superior and middle temporal gyrus (STG), controls showed no significant modulation of activity but, once again, FHR participants exhibited association-induced enhancement.

In addition to extracting parameter estimates from the groups separately, we also carried out within-group analyses in control and FHR participants separately, across the whole brain. Controls exhibited significantly reduced activity in the inferior frontal and dorsolateral prefrontal regions (BA 44-46) and cerebellar regions bilaterally (with larger spatial extent of suppression on the left side) to the associated than the unrelated word pairs $(\mathrm{p}<0.05)$. In contrast, FHR participants exhibited significant association-induced suppression in the frontomedial cortex (bilaterally) and the cerebellum, and association-induced enhancement in the superior temporal gyrus (STG) bilaterally $(\mathrm{p}<0.05)$.

\subsection{Correlation between brain activity with behavioral priming and schizotypal traits}

In controls only, the extent of association-induced suppression in the left IFG cluster (or the difference between parameter estimates extracted from the Unrelated vs. Associated condition)was correlated with the semantic priming effect on lexical decision reaction times (Unrelated condition mean RT-Associated condition mean RT) (Fig. 2A). In participants with FHR only, parameter estimates extracted from the left IFG cluster (Unrelated condition compared to baseline fixation) were correlated with the number of global SIS scores $>2$ (Fig. 2B). Other correlations between fMRI parameter estimates and behavioral variables (behavioral priming or schizotypal traits) were not significant.

\section{Discussion}

In this study, we demonstrate that people at FHR for SZ (FHR) show abnormal hemodynamic response enhancement in regions that were expected to show suppression in response to semantic association (a reverse priming effect). Participants with FHR showed association-induced enhancement in the left inferior frontal, right superior/middle temporal and left cerebellar regions, while controls showed the expected association-induced suppression of activity in frontal and cerebellar regions. The groups were comparable in behavioral semantic priming, demographic variables and IQ, suggesting that group differences in brain activity were not driven by differences in task performance or potentially confounding factors.

\subsection{Reversed priming effect in participants with FHR}

In controls, the majority of semantic priming studies report association-induced suppression in frontal and/or temporal cortices (Kotz et al., 2002; Copland et al., 2003; Rissman et al., 2003; Matsumoto et al., 2005; Wheatley et al., 2005; Kuperberg et al., 2008b). An 
associated prime is thought to pre-activate semantic features that are shared by the target (Neely, 1991), leading to reduced activity within temporal cortices where such semantic features and lexical representations are thought to be accessed (Martin, 2007; Patterson et al., 2007; Lau et al., in press). This, in turn, imposes fewer demands on actively retrieving the semantic features of the target, and there is also less need to suppress irrelevant semantic features activated by an unrelated prime, leading to reduced activity within frontal cortices.

Kuperberg et al. (2007) suggested that the reverse priming effect seen in SZ stemmed from an abnormal increase in lexico-semantic activity. On this account, rather than facilitate recognition of the target, semantic features activated by the associated prime competed with features activated by the target, placing more selection demands on the frontal cortices in the Associated condition than in the Unrelated condition (for further discussion of how different degrees of lexical activity can lead to either facilitation or interference, see Chen and Mirman, 2012). Also of potential relevance, reverse priming effects have been observed in studies of controls when stimulus perception is impaired (Turk-Browne et al., 2007), and when attention to the stimulus, the perceived task-relevance of stimuli, and self-monitoring play important roles (Brown and Aggleton, 2001; Kouider et al., 2007; Nakamura et al., 2007; Segaert et al., 2013).

The present findings indicate that similar mechanisms may be at play in FHR. Here, we again saw evidence of increased temporal activity (interestingly on the right), as well as increased frontal activity in the Associated (versus Unrelated) condition. Prefrontal hyperactivity in FHR has been reported in a wide variety of tasks with executive demands (even when participants with FHR perform tasks at levels comparable to controls) (reviewed in (Thermenos et al., 2013)). More generally, abnormal frontal-temporal activity (including altered lateralization of function) has been observed in several previous fMRI studies of this group using diverse language tasks (Kubicki et al., 2003; Sommer et al., 2004; Whalley et al., 2004; Li et al., 2007a, 2007b, 2009; Rajarethinam et al., 2011) sometimes in association with symptoms or cognitive decline (Lymer et al., 2006; Bhojraj et al., 2009; Whalley et al., 2009; Oertel et al., 2010; Bhojraj et al., 2011). Our findings are also broadly consistent with structural studies reporting gray (Bhojraj et al., 2009; Goghari et al., 2011; Li et al., 2012) as well as white matter (McIntosh et al., 2004) alterations in frontal and temporal regions in participants with FHR.

\subsection{Relationship of altered brain activity to symptoms in participants with FHR}

In the inferior frontal gyrus (IFG), participants with FHR showed hyperactivity in response to both unrelated and associated words, and the extent of IFG hyperactivity to unrelated words was associated with the number of clinically meaningful scores on the Structured Interview for Schizotypy (SIS) in participants with FHR. While the precise functional interpretation of this observation is somewhat unclear, it may reflect a neural basis of risk for developing unusual ideas, perceptions and disorganized language (Grimshawet al., 2010). Previous studies have also reported relationships between abnormal frontal modulation during language processing and clinical symptoms in participants with FHR and SZ (Whyte et al., 2006; Han et al., 2007), (including a relationship between reduced IFG suppression during semantic priming and clinical symptoms in SZ) (Han et al., 2007). The 
extent of IFG non-suppression during semantic priming could potentially reflect a continuum of risk for SZ, with moderate levels of non-suppression associated with attenuated positive symptoms, and higher levels, with frank psychosis.

\subsection{Future research}

Our findings raise important questions for future research. To further understand the temporal and spatial architecture of reverse priming deficits in participants with FHR, future studies can combine the spatial resolution of fMRI with the temporal resolution of ERP and/or MEG, using SOAs of different lengths to test different hypotheses. Examination of frontotemporal functional connectivity during associative processing (as well as its relationship to the structure of underlying white matter tracts) will also be an important area for further study. The extent of frontotemporal enhancement in participants with FHR could potentially predict which individuals are at greater risk to develop a psychotic disorder, as suggested by previous work (Lymer et al., 2006; Bhojraj et al., 2009; Whalley et al., 2009; Oertel et al., 2010; Bhojraj et al., 2011). Future longitudinal studies are needed to test this hypothesis and to determine precisely which abnormalities predict which individuals go on to develop symptoms of and/or functional deficits.

\subsection{Limitations}

The semantic priming effect itself is quite subtle, and there was only a modest difference in brain activity in control and FHR participants (even with a relatively large sample size). There were several other brain regions exhibiting marginal group differences that did not meet criteria for statistical significance in this study. Indeed, effects in FHR participants tend to be subtle, as subjects in the study were non-psychotic (with a small percentage expected to eventually develop a psychotic disorder).

Another limitation of study was the lack of fine-grained quantitative measures of schizotypal traits and positive and negative symptoms, for use in covariance analyses. Finally, due to the close temporal proximity of the prime and target stimuli in our semantic priming task, it is not possible to differentiate neural responses to primes vs. targets using fMRI. Thus, the differential modulation observed between FHR and control participants reflects a combination of responses to the prime and target. Future studies should employ multi-modal technologies (MRI, ERPs and MEG) to improve our understanding of the neural responses to primes and targets in risk for SZ.

In summary, this was the first fMRI study, to our knowledge, to examine semantic priming in non-psychotic participants with FHR. We demonstrated altered semantic associationinduced modulation of frontotemporal activity in a relatively large sample of participants with FHR, as well as a relationship of IFG activity to schizotypal traits in this group. This suggests that 1) semantic association-induced frontotemporal enhancement is a potential marker of neurobiological risk for SZ, and 2) this abnormal modulation of brain activity might increase risk to develop unusual ideas and perceptions that characterize schizotypal disorders (Grimshaw et al., 2010). 


\section{Acknowledgments}

We thank the families who donated their time to this study, and our colleagues and project staff for their insightful comments on the manuscript and generous contributions to the study: Samantha DiChiara, Sneha Suresh, Lauren Beaton, and Lynda Tucker.

\section{Funding source}

This project was funded by NIH R21 MH 083205 (LD), R21 MH 64023 (LD), R01 MH 78113 (MSK), R01 MH 071635 (GRK), R01 MH 074794 (MK), and R01 AG 042512 (MK) and the Commonwealth Research Center of the Massachusetts Department of Mental Health, SCDMH82101008006 (LJS). This research was carried out in part at the Athinoula A. Martinos Center for Biomedical Imaging at the Massachusetts General Hospital, using resources provided by the Center for Functional Neuroimaging Technologies, P41EB015896, a P41 Regional Resource supported by the National Institute of Biomedical Imaging and Bioengineering (NIBIB), National Institutes of Health. This work also involved the use of instrumentation supported by the NIH Shared Instrumentation Grant Program and/or High-End Instrumentation Grant Program; specifically, grant number(s) S10RR021110.

\section{References}

Andreasen NC. Thought, language, and communication disorders. I. Clinical assessment, definition of terms, and evaluation of their reliability. Arch. Gen. Psychiatry. 1979; 36(12):1315-1321. [PubMed: 496551]

Annett M. A classification of hand preference by association analysis. Br. J. Psychol. 1970; 61(3):303321. [PubMed: 5457503]

Barch DM, Cohen JD, Servan-Schreiber D, Steingard S, Cohen JD, Steinhauer SS, van Kammen DP. Semantic priming in schizophrenia: an examination of spreading activation using word pronunciation and multiple SOAs. J. Abnorm. Psychol. 1996; 105(4):592-601. [PubMed: 8952192]

Bartzokis G, Nuechterlein KH, Lu PH, Gitlin M, Rogers S, Mintz J. Dysregulated brain development in adult men with schizophrenia: a magnetic resonance imaging study. Biol. Psychiatry. 2003; 53(5):412-421. [PubMed: 12614994]

Besche-Richard C, Passerieux C, Hardy-Bayle MC. Double-decision lexical tasks in thoughtdisordered schizophrenic patients: a path towards cognitive remediation? Brain Lang. 2005; 95(3): 395-401. [PubMed: 16298669]

Bhojraj TS, Francis AN, Rajarethinam R, Eack S, Kulkarni S, Prasad KM, Montrose DM, Dworakowski D, Diwadkar V, Keshavan MS. Verbal fluency deficits and altered lateralization of language brain areas in individuals genetically predisposed to schizophrenia. Schizophr. Res. 2009; 115(2-3):202-208. [PubMed: 19840895]

Bhojraj TS, Francis AN, Montrose DM, Keshavan MS. Grey matter and cognitive deficits in young relatives of schizophrenia patients. NeuroImage. 2011; 54(Suppl. 1):S287-S292. [PubMed: 20362681]

Bleuler, E. Dementia Praecox or the Group of Schizophrenias. New York: International Universities Press; 1950.

Brown MW, Aggleton JP. Recognition memory: what are the roles of the perirhinal cortex and hippocampus? Nat. Rev. Neurosci. 2001; 2(1):51-61. [PubMed: 11253359]

Burns J, Job D, Bastin ME, Whalley H, Macgillivray T, Johnstone EC, Lawrie SM. Structural disconnectivity in schizophrenia: a diffusion tensor magnetic resonance imaging study. Br. J. Psychiatry. 2003; 182:439-443. [PubMed: 12724248]

Burock MA, Buckner RL, Woldorff MG, Rosen BR, Dale AM. Randomized event-related experimental designs allow for extremely rapid presentation rates using functional MRI. Neuroreport. 1998; 9(16):3735-3739. [PubMed: 9858388]

Cannon M, Caspi A, Moffitt TE, Harrington H, Taylor A, Murray RM, Poulton R. Evidence for earlychildhood, pan-developmental impairment specific to schizophreniform disorder: results from a longitudinal birth cohort. Arch. Gen. Psychiatry. 2002; 59(5):449-456. [PubMed: 11982449]

Chen Q, Mirman D. Competition and cooperation among similar representations: toward a unified account of facilitative and inhibitory effects of lexical neighbors. Psychol. Rev. 2012; 119(2):417430. [PubMed: 22352357] 
Copland DA, de Zubicaray GI, McMahon K, Wilson SJ, Eastburn M, Chenery HJ. Brain activity during automatic semantic priming revealed by event-related functional magnetic resonance imaging. NeuroImage. 2003; 20(1):302-310. [PubMed: 14527590]

Crow TJ. Schizophrenia as failure of hemispheric dominance for language. Trends Neurosci. 1997; 20(8):339-343. [PubMed: 9246721]

Crow TJ. The 'big bang' theory of the origin of psychosis and the faculty of language. Schizophr. Res. 2008; 102(1-3):31-52. [PubMed: 18502103]

Cui LQ, Deng W, Jiang LJ, Huang CH, Chen ZF, Li ML, Gong QY, Li T. A comparative study of voxel-based morphometry in patients with paranoid schizophrenia and bipolar mania. Sichuan Da Xue Xue Bao Yi Xue Ban. 2010; 41(1):5-9. [PubMed: 20369460]

Cui L, Li M, Deng W, Guo W, Ma X, Huang C, Jiang L, Wang Y, Collier DA, Gong Q, Li T. Overlapping clusters of gray matter deficits in paranoid schizophrenia and psychotic bipolar mania with family history. Neurosci. Lett. 2011; 489(2):94-98. [PubMed: 21138758]

DeLisi LE, Boccio AM, Riordan H, Hoff AL, Dorfman A, McClelland J, Kushner M, Van Eyl O, Oden N. Familial thyroid disease and delayed language development in first admission patients with schizophrenia. Psychiatry Res. 1991; 38(1):39-50. [PubMed: 1946833]

First, MB.; Spitzer, RL.; Gibbon, M.; Williams, JWB. Structured Clinical Interview for DSM-IV Axis I Disorders - Patient Edition, Version 2. Washington, D.C.: American Psychiatric Press; 1996.

Fuller R, Nopoulos P, Arndt S, O'Leary D, Ho BC, Andreasen NC. Longitudinal assessment of premorbid cognitive functioning in patients with schizophrenia through examination of standardized scholastic test performance. Am. J. Psychiatry. 2002; 159(7):1183-1189. [PubMed: 12091197]

Goghari VM, Macdonald AW III, Sponheim SR. Temporal lobe structures and facial emotion recognition in schizophrenia patients and nonpsychotic relatives. Schizophr. Bull. 2011; 37(6): 1281-1294. [PubMed: 20484523]

Gold BT, Balota DA, Jones SJ, Powell DK, Smith CD, Andersen AH. Dissociation of automatic and strategic lexical-semantics: functional magnetic resonance imaging evidence for differing roles of multiple frontotemporal regions. J. Neurosci. 2006; 26(24):6523-6532. [PubMed: 16775140]

Goldberg TE, Aloia MS, Gourovitch ML, Missar D, Pickar D, Weinberger DR. Cognitive substrates of thought disorder, I: the semantic system. Am. J. Psychiatry. 1998; 155(12):1671-1676. [PubMed: 9842774]

Grimshaw GM, Bryson FM, Atchley RA, Humphrey MK. Semantic ambiguity resolution in positive schizotypy: a right hemisphere interpretation. Neuropsychology. 2010; 24(1):130-138. [PubMed: 20063954]

Hallett S, Quinn D, Hewitt J. Defective interhemispheric integration and anomalous language lateralization in children at risk for schizophrenia. J. Nerv. Ment. Dis. 1986; 174(7):418-427. [PubMed: 3723128]

Han SD, Nestor PG, Hale-Spencer M, Cohen A, Niznikiewicz M, McCarley RW, Wible CG. Functional neuroimaging of word priming in males with chronic schizophrenia. NeuroImage. 2007; 35(1):273-282. [PubMed: 17215145]

Hoff AL, Sakuma M, Wieneke M, Horon R, Kushner M, DeLisi LE. Longitudinal neuropsychological follow-up study of patients with first-episode schizophrenia. Am. J. Psychiatry. 1999; 156(9): 1336-1341. [PubMed: 10484942]

Hoff AL, Svetina C, Shields G, Stewart J, DeLisi LE. Ten year longitudinal study of neuropsychological functioning subsequent to a first episode of schizophrenia. Schizophr. Res. 2005; 78(1):27-34. [PubMed: 15964177]

Honer WG, Bassett AS, Squires-Wheeler E, Falkai P, Smith GN, Lapointe JS, Canero C, Lang DJ. The temporal lobes, reversed asymmetry and the genetics of schizophrenia. Neuroreport. 1995; 7(1): 221-224. [PubMed: 8742456]

Hubl D, Koenig T, Strik W, Federspiel A, Kreis R, Boesch C, Maier SE, Schroth G, Lovblad K, Dierks T. Pathways that make voices: white matter changes in auditory hallucinations. Arch. Gen. Psychiatry. 2004; 61(7):658-668. [PubMed: 15237078]

Jones DK, Catani M, Pierpaoli C, Reeves SJ, Shergill SS, O'Sullivan M, Golesworthy P, McGuire P, Horsfield MA, Simmons A, Williams SC, Howard RJ. Age effects on diffusion tensor magnetic 
resonance imaging tractography measures of frontal cortex connections in schizophrenia. Hum. Brain Mapp. 2006; 27(3):230-238. [PubMed: 16082656]

Kendler KS, Lieberman JA, Walsh D. The Structured Interview for Schizotypy (SIS): a preliminary report. Schizophr. Bull. 1989; 15(4):559-571. [PubMed: 2623438]

Kotz SA, Cappa SF, von Cramon DY, Friederici AD. Modulation of the lexical-semantic network by auditory semantic priming: an event-related functional MRI study. NeuroImage. 2002; 17(4): 1761-1772. [PubMed: 12498750]

Kouider S, Dehaene S, Jobert A, Le Bihan D. Cerebral bases of subliminal and supraliminal priming during reading. Cereb. Cortex. 2007; 17(9):2019-2029. [PubMed: 17101688]

Kreher DA, Holcomb PJ, Kuperberg GR. An electrophysiological investigation of indirect semantic priming. Psychophysiology. 2006; 43(6):550-563. [PubMed: 17076811]

Kreher DA, Holcomb PJ, Goff D, Kuperberg GR. Neural evidence for faster and further automatic spreading activation in schizophrenic thought disorder. Schizophr. Bull. 2008; 34(3):473-482. [PubMed: 17905785]

Kreher DA, Goff D, Kuperberg GR. Why all the confusion? Experimental task explains discrepant semantic priming effects in schizophrenia under "automatic" conditions: evidence from eventrelated potentials. Schizophr. Res. 2009; 111(1-3):174-181. [PubMed: 19386472]

Kubicki M, Westin CF, Maier SE, Frumin M, Nestor PG, Salisbury DF, Kikinis R, Jolesz FA, McCarley RW, Shenton ME. Uncinate fasciculus findings in schizophrenia: a magnetic resonance diffusion tensor imaging study. Am. J. Psychiatry. 2002; 159(5):813-820. [PubMed: 11986136]

Kubicki M, McCarley RW, Nestor PG, Huh T, Kikinis R, Shenton ME, Wible CG. An fMRI study of semantic processing in men with schizophrenia. NeuroImage. 2003; 20(4):1923-1933. [PubMed: 14683698]

Kubicki M, Alvarado JL, Westin CF, Tate DF, Markant D, Terry DP, Whitford TJ, De Siebenthal J, Bouix S, McCarley RW, Kikinis R, Shenton ME. Stochastic tractography study of inferior frontal gyrus anatomical connectivity in schizophrenia. NeuroImage. 2011; 55(4):1657-1664. [PubMed: 21256966]

Kuperberg GR. Language in schizophrenia part 1: an introduction. Lang. Linguist. Compass. 2010a; 4(8):576-589. [PubMed: 20936080]

Kuperberg GR. Language in schizophrenia part 2: what can psycholinguistics bring to the study of schizophrenia... and vice versa? Lang. Linguist. Compass. 2010b; 4(8):590-604. [PubMed: 20824153]

Kuperberg, GR.; Goldberg, T. Insights into semantics and language in schizophrenia. In: Wood, S.; Allen, N.; Pantelis, C., editors. Handbook of Neuropsychology of Mental Illness. Cambridge University Press; 2006.

Kuperberg GR, Broome MR, McGuire PK, David AS, Eddy M, Ozawa F, Goff D, West WC, Williams SC, van der Kouwe AJ, Salat DH, Dale AM, Fischl B. Regionally localized thinning of the cerebral cortex in schizophrenia. Arch. Gen. Psychiatry. 2003; 60(9):878-888. [PubMed: 12963669]

Kuperberg GR, Deckersbach T, Holt DJ, Goff D, West WC. Increased temporal and prefrontal activity in response to semantic associations in schizophrenia. Arch. Gen. Psychiatry. 2007; 64(2):138151. [PubMed: 17283282]

Kuperberg, GR.; Ditman, T.; Kreher, DA.; Goldberg, T. Approaches to understanding language dysfunction in neuropsychiatric disorders: insights from the study of schizophrenia. In: Wood, S.; Allen, N.; Pantelis, C., editors. Handbook of Neuropsychology of Mental Illness. Cambridge University Press; 2008a.

Kuperberg GR, Lakshmanan BM, Greve DN, West WC. Task and semantic relationship influence both the polarity and localization of hemodynamic modulation during lexico-semantic processing. Hum. Brain Mapp. 2008b; 29(5):544-561. [PubMed: 17674356]

Kuperberg GR, West WC, Lakshmanan BM, Goff D. Functional magnetic resonance imaging reveals neuroanatomical dissociations during semantic integration in schizophrenia. Biol. Psychiatry. 2008c; 64(5):407-418. [PubMed: 18504037]

Lau EF, Phillips C, Poeppel D. A cortical network for semantics: (de)constructing the N400. Nat. Rev. Neurosci. 2008; 9(12):920-933. [PubMed: 19020511] 
Lau EF, Gramfort A, Hämäläinen MS, Kuperberg GR. Automatic semantic facilitation in anterior temporal cortex revealed through multimodal neuroimaging. J. Neurosci. 2013 (in press).

Lecardeur L, Giffard B, Eustache F, Dollfus S. Schizophrenia and semantic priming effects. L'Encéphale. 2006; 32(1 Pt 1):75-82.

Li X, Branch CA, Ardekani BA, Bertisch H, Hicks C, DeLisi LE. fMRI study of language activation in schizophrenia, schizoaffective disorder and in individuals genetically at high risk. Schizophr. Res. 2007a; 96(1-3):14-24. [PubMed: 17719745]

Li X, Branch CA, Bertisch HC, Brown K, Szulc KU, Ardekani BA, DeLisi LE. An fMRI study of language processing in people at high genetic risk for schizophrenia. Schizophr. Res. 2007b; 91(13):62-72. [PubMed: 17306963]

Li X, Branch CA, DeLisi LE. Language pathway abnormalities in schizophrenia: a review of fMRI and other imaging studies. Curr. Opin. Psychiatry. 2009; 22(2):131-139. [PubMed: 19553866]

Li X, Branch CA, Nierenberg J, Delisi LE. Disturbed functional connectivity of cortical activation during semantic discrimination in patients with schizophrenia and subjects at genetic high-risk. Brain Imaging Behav. 2010; 4(1):109-120. [PubMed: 20503118]

Li X, Alapati V, Jackson C, Xia S, Bertisch HC, Branch CA, Delisi LE. Structural abnormalities in language circuits in genetic high-risk subjects and schizophrenia patients. Psychiatry Res. 2012; 201(3):182-189. [PubMed: 22512952]

Lymer GK, Job DE, William T, Moorhead J, McIntosh AM, Owens DG, Johnstone EC, Lawrie SM. Brain-behaviour relationships in people at high genetic risk of schizophrenia. NeuroImage. 2006; 33(1):275-285. [PubMed: 16926102]

Maher BA, Manschreck TC, Linnet J, Candela S. Quantitative assessment of the frequency of normal associations in the utterances of schizophrenia patients and healthy controls. Schizophr. Res. 2005; 78(2-3):219-224. [PubMed: 16005190]

Manschreck TC, Maher BA, Milavetz JJ, Ames D, Weisstein CC, Schneyer ML. Semantic priming in thought disordered schizophrenic patients. Schizophr. Res. 1988; 1(1):61-66. [PubMed: 3154508]

Martin A. The representation of object concepts in the brain. Annu. Rev. Psychol. 2007; 58:25-45. [PubMed: 16968210]

Matsumoto A, Iidaka T, Haneda K, Okada T, Sadato N. Linking semantic priming effect in functional MRI and event-related potentials. NeuroImage. 2005; 24(3):624-634. [PubMed: 15652298]

McIntosh AM, Job DE, Moorhead TW, Harrison LK, Forrester K, Lawrie SM, Johnstone EC. Voxelbased morphometry of patients with schizophrenia or bipolar disorder and their unaffected relatives. Biol. Psychiatry. 2004; 56(8):544-552. [PubMed: 15476683]

McNair, D.; Lorr, M.; Droppleman, L. EdITS Manual for the Profile of Mood States. San Diego, CA: Educational and Industrial Testing Service; 1992.

Meyer DE, Schvaneveldt RW. Facilitation in recognizing pairs of words: evidence of a dependence between retrieval operations. J. Exp. Psychol. 1971; 90(2):227-234. [PubMed: 5134329]

Moritz S, Mersmann K, Kloss M, Jacobsen D, Andresen B, Krausz M, Pawlik K, Naber D. Enhanced semantic priming in thought-disordered schizophrenic patients using a word pronunciation task. Schizophr. Res. 2001a; 48(2-3):301-305. [PubMed: 11295382]

Moritz S, Mersmann K, Kloss M, Jacobsen D, Wilke U, Andresen B, Naber D, Pawlik K. 'Hyperpriming' in thought-disordered schizophrenic patients. Psychol. Med. 2001b; 31(2):221-229. [PubMed: 11232910]

Nakamura K, Dehaene S, Jobert A, Le Bihan D, Kouider S. Task specific change of unconscious neural priming in the cerebral language network. Proc. Natl. Acad. Sci. U. S. A. 2007; 104(49): 19643-19648. [PubMed: 18042726]

Neely, JH. Semantic priming effects in visual word recognition: a selective review of current findings and theories. In: Besner, D.; Humphreys, GW., editors. Basic Processes in Reading and Visual Word Recognition. Hillsdale, NJ: Erlbaum; 1991. p. 264-333.

Nurnberger JI Jr, Blehar MC, Kaufmann CA, York-Cooler C, Simpson SG, Harkavy-Friedman J, Severe JB, Malaspina D, Reich T. Diagnostic interview for genetic studies. Rationale, unique features, and training. NIMH Genetics Initiative. Arch. Gen. Psychiatry. 1994; 51(11):849-859. (discussion 863-844). [PubMed: 7944874] 
Ober BA, Vinogradov S, Shenaut GK. Automatic versus controlled semantic priming in schizophrenia. Neuropsychology. 1997; 11(4):506-513. [PubMed: 9345694]

Oertel V, Knochel C, Rotarska-Jagiela A, Schonmeyer R, Lindner M, van de Ven V, Haenschel C, Uhlhaas P, Maurer K, Linden DE. Reduced laterality as a trait marker of schizophrenia - evidence from structural and functional neuroimaging. J. Neurosci. 2010; 30(6):2289-2299. [PubMed: 20147555]

Ott SL, Allen J, Erlenmeyer-Kimling L. The New York High-Risk Project: observations on the rating of early manifestations of schizophrenia. Am. J.Med. Genet. 2001; 105(1):25-27. [PubMed: 11424987]

Pantelis C, Yucel M, Wood SJ, McGorry PD, Velakoulis D. Early and late neurodevelopmental disturbances in schizophrenia and their functional consequences. Aust. N. Z. J. Psychiatry. 2003; 37(4):399-406. [PubMed: 12873323]

Patterson K, Nestor PJ, Rogers TT. Where do you know what you know? The representation of semantic knowledge in the human brain. Nat. Rev. Neurosci. 2007; 8(12):976-987. [PubMed: 18026167]

Petty RG, Barta PE, Pearlson GD, McGilchrist IK, Lewis RW, Tien AY, Pulver A, Vaughn DD, Casanova MF, Powers RE. Reversal of asymmetry of the planum temporale in schizophrenia. Am. J. Psychiatry. 1995; 152(5):715-721. [PubMed: 7726311]

Pomarol-Clotet E, Oh TM, Laws KR, McKenna PJ. Semantic priming in schizophrenia: systematic review and meta-analysis. Br. J. Psychiatry. 2008; 192(2):92-97. [PubMed: 18245021]

Ragland JD, Gur RC, Valdez J, Turetsky BI, Elliott M, Kohler C, Siegel S, Kanes S, Gur RE. Eventrelated fMRI of frontotemporal activity during word encoding and recognition in schizophrenia. Am. J. Psychiatry. 2004; 161(6):1004-1015. [PubMed: 15169688]

Rajarethinam R, Sahni S, Rosenberg DR, Keshavan MS. Reduced superior temporal gyrus volume in young offspring of patients with schizophrenia. Am. J. Psychiatry. 2004; 161(6):1121-1124. [PubMed: 15169705]

Rajarethinam R, Venkatesh BK, Peethala R, Phan KL, Keshavan M. Reduced activation of superior temporal gyrus during auditory comprehension in young offspring of patients with schizophrenia. Schizophr. Res. 2011; 130(1-3):101-105. [PubMed: 21684722]

Rissman J, Eliassen JC, Blumstein SE. An event-related FMRI investigation of implicit semantic priming. J. Cogn. Neurosci. 2003; 15(8):1160-1175. [PubMed: 14709234]

Sanfilipo M, Lafargue T, Rusinek H, Arena L, Loneragan C, Lautin A, Feiner D, Rotrosen J, Wolkin A. Volumetric measure of the frontal and temporal lobe regions in schizophrenia: relationship to negative symptoms. Arch. Gen. Psychiatry. 2000; 57(5):471-480. [PubMed: 10807487]

Segaert K, Weber K, de Lange FP, Petersson KM, Hagoort P. The suppression of repetition enhancement: a review of fMRI studies. Neuropsychologia. 2013; 51(1):59-66. [PubMed: 23159344]

Shenton ME, Dickey CC, Frumin M, McCarley RW. A review of MRI findings in schizophrenia. Schizophr. Res. 2001; 49(1-2):1-52. [PubMed: 11343862]

Skudlarski P, Jagannathan K, Anderson K, Stevens MC, Calhoun VD, Skudlarska BA, Pearlson G. Brain connectivity is not only lower but different in schizophrenia: a combined anatomical and functional approach. Biol. Psychiatry. 2010; 68(1):61-69. [PubMed: 20497901]

Sommer IE, Ramsey NF, Kahn RS. Language lateralization in schizophrenia, an fMRI study. Schizophr. Res. 2001; 52(1-2):57-67. [PubMed: 11595392]

Sommer IE, Ramsey NF, Mandl RC, Kahn RS. Language lateralization in female patients with schizophrenia: an fMRI study. Schizophr. Res. 2003; 60(2-3):183-190. [PubMed: 12591582]

Sommer IE, Ramsey NF, Mandl RC, van Oel CJ, Kahn RS. Language activation in monozygotic twins discordant for schizophrenia. Br. J. Psychiatry. 2004; 184:128-135. [PubMed: 14754824]

Spitzer M, Braun U, Hermle L, Maier S. Associative semantic network dysfunction in thoughtdisordered schizophrenic patients: direct evidence from indirect semantic priming. Biol. Psychiatry. 1993; 34(12):864-877. [PubMed: 8110913]

Spitzer M, Weisker I, Winter M, Maier S, Hermle L, Maher BA. Semantic and phonological priming in schizophrenia. J. Abnorm. Psychol. 1994; 103(3):485-494. [PubMed: 7930048] 
Thermenos HW, Keshavan MS, Juelich RJ, Molokotos EM, Whitfield-Gabrieli S, Brent BK, Makris $\mathrm{N}$, Seidman LJ. A review of neuroimaging studies of young relatives of individuals with schizophrenia: a developmental perspective from schizotaxia to schizophrenia. Am. J. Med. Genet. B Neuropsychiatr. Genet. 2013; Part B 162B(7):604-635. [PubMed: 24132894]

Thesen S, Heid O, Mueller E, Schad LR. Prospective acquisition correction for head motion with image-based tracking for real-time fMRI. Magn. Reson. Med. 2000; 44(3):457-465. [PubMed: 10975899]

Thompson-Schill SL, D'Esposito M, Aguirre GK, Farah MJ. Role of left inferior prefrontal cortex in retrieval of semantic knowledge: a reevaluation. Proc. Natl. Acad. Sci. U. S. A. 1997; 94(26): 14792-14797. [PubMed: 9405692]

Thompson-Schill SL, D'Esposito M, Kan IP. Effects of repetition and competition on activity in left prefrontal cortex during word generation. Neuron. 1999; 23(3):513-522. [PubMed: 10433263]

Titone D, Levy DL, Holzman PS. Contextual insensitivity in schizophrenic language processing: evidence from lexical ambiguity. J. Abnorm. Psychol. 2000; 109(4):761-767. [PubMed: 11196002]

Turk-Browne NB, Yi DJ, Leber AB, Chun MM. Visual quality determines the direction of neural repetition effects. Cereb. Cortex. 2007; 17(2):425-433. [PubMed: 16565294]

Van Petten C, Luka BJ. Neural localization of semantic context effects in electromagnetic and hemodynamic studies. Brain Lang. 2006; 97(3):279-293. [PubMed: 16343606]

Vinogradov S, Ober BA, Shenaut GK. Semantic priming of word pronunciation and lexical decision in schizophrenia. Schizophr. Res. 1992; 8(2):171-181. [PubMed: 1457395]

Voineskos AN, Lobaugh NJ, Bouix S, Rajji TK, Miranda D, Kennedy JL, Mulsant BH, Pollock BG, Shenton ME. Diffusion tensor tractography findings in schizophrenia across the adult lifespan. Brain. 2010; 133(Pt 5):1494-1504. [PubMed: 20237131]

Wagner AD, Pare-Blagoev EJ, Clark J, Poldrack RA. Recovering meaning: left prefrontal cortex guides controlled semantic retrieval. Neuron. 2001; 31(2):329-338. [PubMed: 11502262]

Wang F, McIntosh AM, He Y, Gelernter J, Blumberg HP. The association of genetic variation in CACNA1Cwith structure and function of a frontotemporal system. Bipolar Disord. 2011; 13(78):696-700. [PubMed: 22085483]

Wechsler, D. Wechsler Abbreviated Scale of Intellegence. San Antonio, TX: Psychological Corporation; 1999.

Weiss AP, Schacter DL, Goff DC, Rauch SL, Alpert NM, Fischman AJ, Heckers S. Impaired hippocampal recruitment during normal modulation of memory performance in schizophrenia. Biol. Psychiatry. 2003; 53(1):48-55. [PubMed: 12513944]

Whalley HC, Simonotto E, Flett S, Marshall I, Ebmeier KP, Owens DG, Goddard NH, Johnstone EC, Lawrie SM. fMRI correlates of state and trait effects in subjects at genetically enhanced risk of schizophrenia. Brain. 2004; 127(Pt 3):478-490. [PubMed: 14749289]

Whalley HC, Gountouna VE, Hall J, McIntosh AM, Simonotto E, Job DE, Owens DG, Johnstone EC, Lawrie SM. fMRI changes over time and reproducibility in unmedicated subjects at high genetic risk of schizophrenia. Psychol. Med. 2009; 39(7):1189-1199. [PubMed: 19105855]

Wheatley T, Weisberg J, Beauchamp MS, Martin A. Automatic priming of semantically related words reduces activity in the fusiform gyrus. J. Cogn. Neurosci. 2005; 17(12):1871-1885. [PubMed: 16356325]

Whitford TJ, Kubicki M, Schneiderman JS, O'Donnell LJ, King R, Alvarado JL, Khan U, Markant D, Nestor PG, Niznikiewicz M, McCarley RW, Westin CF, Shenton ME. Corpus callosum abnormalities and their association with psychotic symptoms in patients with schizophrenia. Biol. Psychiatry. 2010; 68(1):70-77. [PubMed: 20494336]

Whyte MC, Whalley HC, Simonotto E, Flett S, Shillcock R, Marshall I, Goddard NH, Johnstone EC, Lawrie SM. Event-related fMRI of word classification and successful word recognition in subjects at genetically enhanced risk of schizophrenia. Psychol. Med. 2006; 36(10):1427-1439. [PubMed: 16805929]

Wible CG, Anderson J, Shenton ME, Kricun A, Hirayasu Y, Tanaka S, Levitt JJ, O'Donnell BF, Kikinis R, Jolesz FA, McCarley RW. Prefrontal cortex, negative symptoms, and schizophrenia: an MRI study. Psychiatry Res. 2001; 108(2):65-78. [PubMed: 11738541] 
Wisco JJ, Kuperberg G, Manoach D, Quinn BT, Busa E, Fischl B, Heckers S, Sorensen AG. Abnormal cortical folding patterns within Broca's area in schizophrenia: evidence from structural MRI. Schizophr. Res. 2007; 94(1-3):317-327. [PubMed: 17490861]

Woolf CM. Does the genotype for schizophrenia often remain unexpressed because of canalization and stochastic events during development? Psychol. Med. 1997; 27(3):659-668. [PubMed: 9153686]

Wyatt RJ. Neurodevelopmental abnormalities and schizophrenia. A family affair. Arch. Gen.

Psychiatry. 1996; 53(1):11-15. [PubMed: 8540772] 

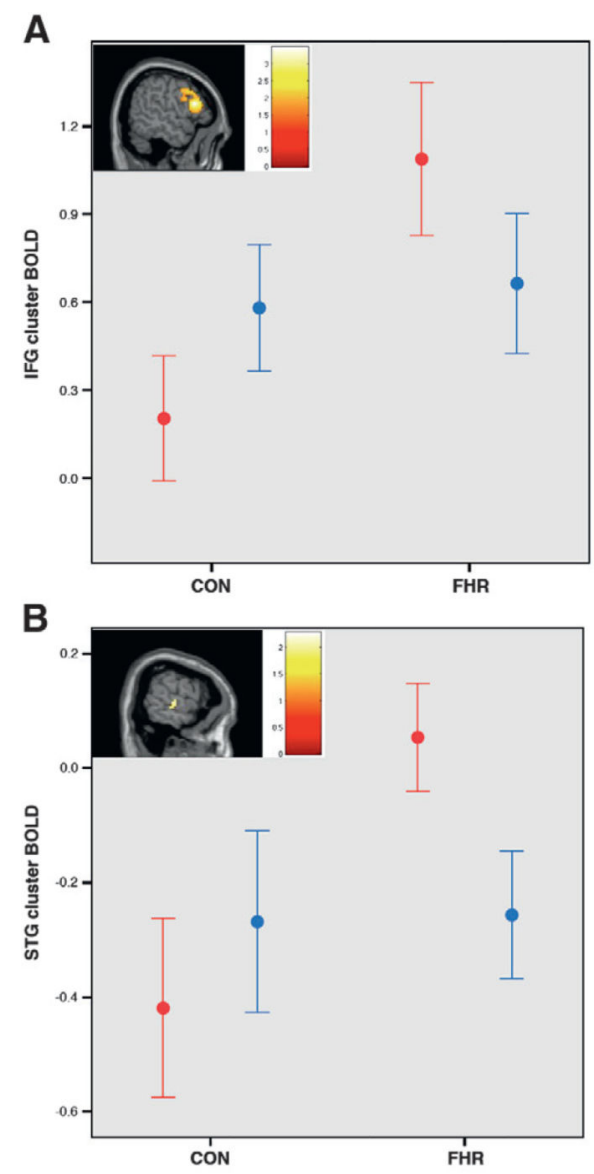

I ASSOCIATED
I UNRELATED

C

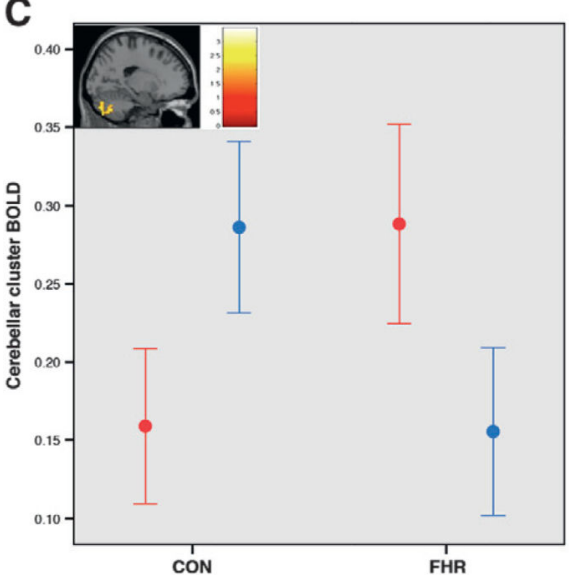

I ASSOCIATED

Fig. 1.

Compared to controls, participants with FHR showed an opposite pattern of hemodynamic modulation to associated versus unrelated word pairs, in the (A) left inferior frontal gyrus (IFG), (B) right superior and middle temporal gyrus (STG) and (C) left cerebellum (group differences $\mathrm{p}<0.05$, family-wise error cluster-level corrected for multiple comparisons). Color bar $=\mathrm{t}$-value. Bar graphs depict parameter estimates extracted from the significant inferior frontal gyrus, superior/middle temporal gyrus and cerebellar clusters for the Associated (red) and Unrelated (blue) word pair conditions, relative to the baseline fixation. 

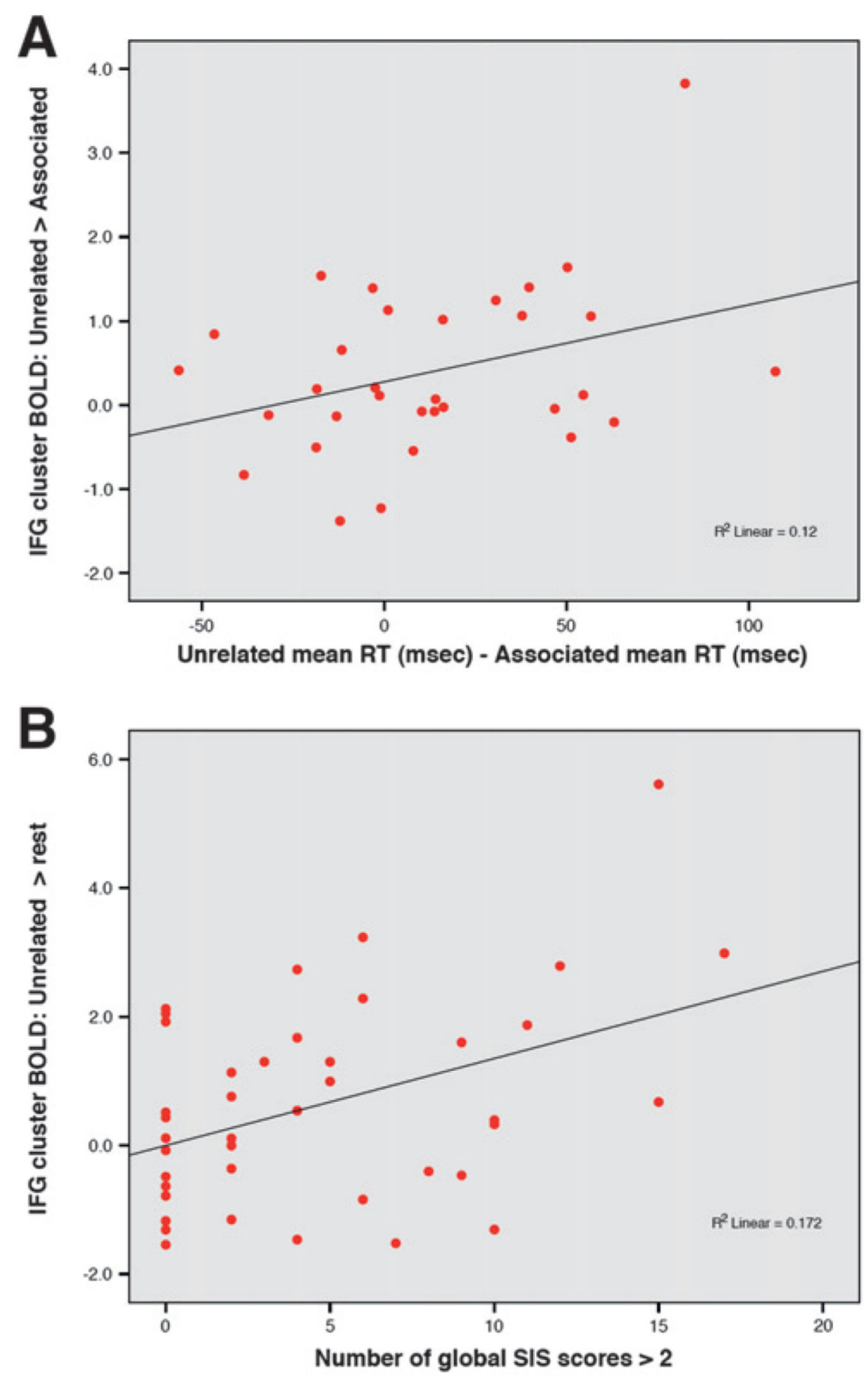

Fig. 2.

(A) Significant correlation $(\mathrm{p}<0.05)$ between association-induced suppression of left inferior frontal gyrus (IFG) activity and semantic priming effect on lexical decision reaction times (RTs) in control participants; (B) Significant correlation ( $\mathrm{p}<0.05)$ between left inferior frontal gyrus (IFG) activity (to Unrelated word pairs relative to baseline fixation) and the number of global Structured Interview for Schizotypy (SIS) scores over 2 in FHR participants. 
Table 1

Demographic, neuropsychological and clinical characteristics of controls (CON) and young people at familial high-risk for schizophrenia (FHR).

\begin{tabular}{|c|c|c|c|}
\hline \multirow[t]{2}{*}{ Variable } & \multirow{2}{*}{$\frac{\operatorname{CON}(n=32)}{\operatorname{Mean}(\mathrm{SD}) \text { or } \%}$} & \multirow{2}{*}{$\frac{\text { FHR }(n=43)}{\text { Mean (SD) or \% }}$} & \multirow{2}{*}{$\frac{\text { CON v. FHR }}{t(p) \text { or } \chi^{2}(p)}$} \\
\hline & & & \\
\hline \multicolumn{4}{|l|}{ Matching variables } \\
\hline Age at MRI & $24.6(2.8)$ & $25.2(3.1)$ & $.93(.36)$ \\
\hline Gender ( $\%$ male) & $41 \%$ & $29 \%$ & $.88(.35)$ \\
\hline Ethnicity (\% cauc.) & $78 \%$ & $69 \%$ & $2.33(.80)$ \\
\hline Handedness (\% right) & $100 \%$ & $100 \%$ & - \\
\hline WRAT-IV $^{a}$ reading & $109.6(12.8)$ & $110.9(12.5)$ & $.41(.69)$ \\
\hline \multicolumn{4}{|l|}{ Education \& $I Q$} \\
\hline Education (years) & $16.0(1.7)$ & $15.6(2.3)$ & $.99(.32)$ \\
\hline \multirow[t]{2}{*}{ IQ estimate $^{b}$} & $117.7(14.7)$ & $116.8(11.4)$ & $.24(.81)$ \\
\hline & Mean (SD) & Mean (SD) & $\mathrm{t}(\mathrm{p})$ \\
\hline \multicolumn{4}{|c|}{ Lexical decision task (in-scanner) } \\
\hline Associated cond. (\% hits) & $98.9 \%$ & $96.3 \%$ & $0.84(.41)$ \\
\hline Unrelated cond.(\% hits) & $98.3 \%$ & $95.1 \%$ & $1.05(.30)$ \\
\hline Associated cond. $\mathrm{RT}^{c}$ & $844(227)$ & 857 (206) & $.26(.80)$ \\
\hline Unrelated cond. $\mathrm{RT}^{c}$ & $857(216)$ & $875(203)$ & $.37(.71)$ \\
\hline \multicolumn{4}{|l|}{ POMS ${ }^{d} T$ scores } \\
\hline Tension/anxiety & $30.9(4.9)$ & $34.4(7.3)$ & $2.32(.02)$ \\
\hline Depression & $36.8(6.1)$ & $39.5(7.7)$ & $1.67(.10)$ \\
\hline Anger/hostility & $41.1(4.9)$ & $44.7(7.3)$ & $2.37(.02)$ \\
\hline Vigor & $64.1(9.5)$ & $61.4(9.1)$ & $1.26(.21)$ \\
\hline Fatigue & $41.4(4.5)$ & $46.2(8.8)$ & $2.98(.009)$ \\
\hline Confusion & $33.7(4.6)$ & $36.2(9.4)$ & $1.39(.17)$ \\
\hline \multicolumn{4}{|l|}{ SISe scores } \\
\hline No. of positive scores & $2.2(2.2)$ & $7.8(7.6)$ & $4.40(.00004)$ \\
\hline No. of scores $>2$ & $1.1(1.5)$ & $5.5(7.0)$ & $3.83(.0002)$ \\
\hline
\end{tabular}

${ }^{a}$ WRAT-3, Wide Range Achievement Test-Third Edition.

${ }^{b}$ Full Scale IQ assessed using the Wechsler Adult Intelligence Scale-III prorated from eight sub-tests.

$c_{\text {Milliseconds. }}$

$d_{\text {Profile of mood states. }}$

${ }^{e}$ Structured Interview for Schizotypy. 


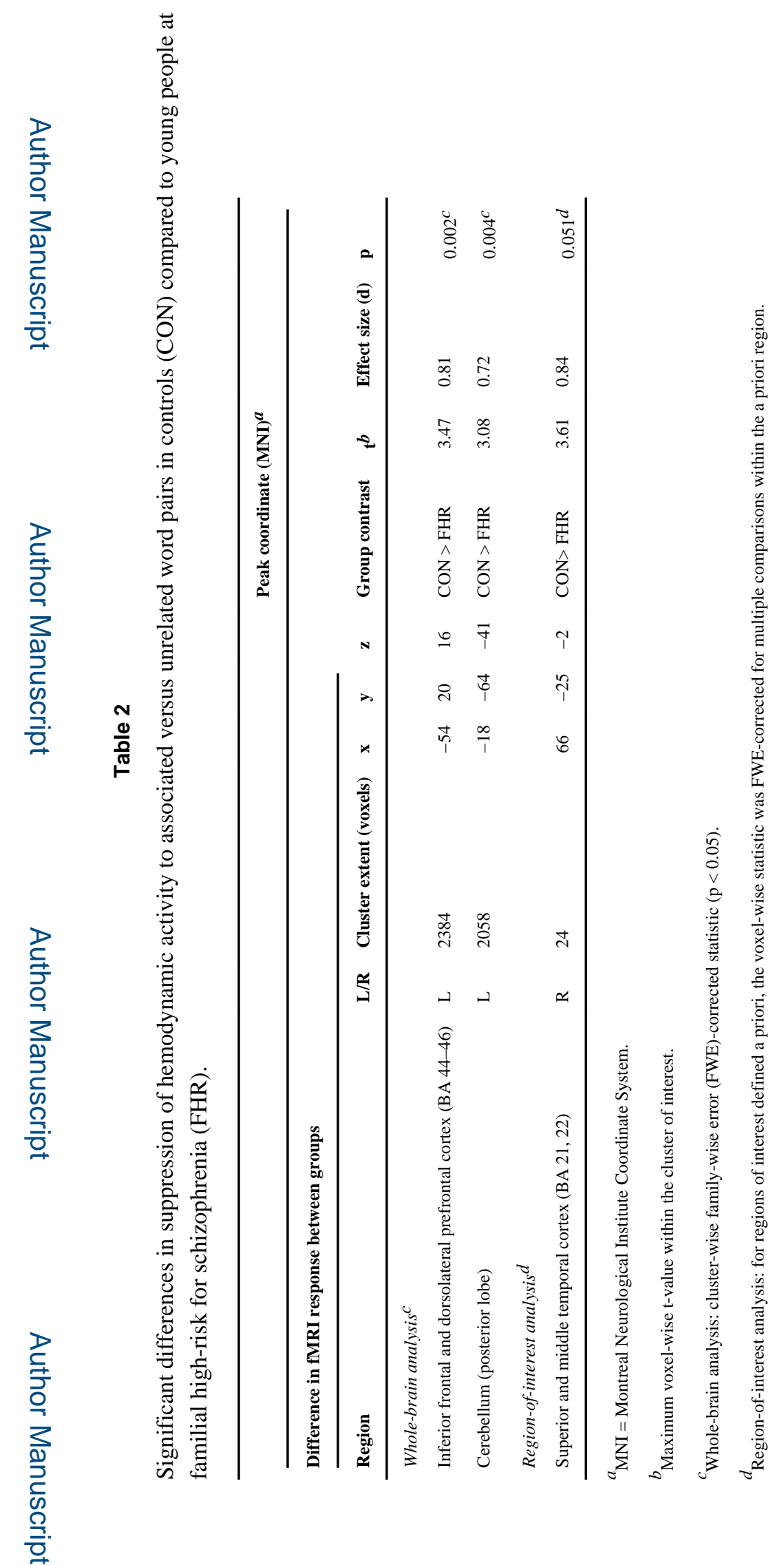

Schizophr Res. Author manuscript; available in PMC 2014 December 01. 